\title{
Device for biaxial testing in uniaxial machines. Design, manufacturing and experimental results using cruciform specimens of composite materials.
}

\author{
A. Barroso, E. Correa, J. Freire, D. Vega, F. París \\ Group ofElasticity and Strength ofMaterials, School ofEngineering, University of \\ Seville, Spain.
}

\begin{abstract}
The present work deals with the design and manufacturing of a mechanical device to perform biaxial testing in universal (uniaxial) testing machines. A review of previous similar proposals is carried out and a new proposal of a device is suggested, allowing tension-tension, compression-compression and tension-compression biaxial testing to be used in single axis machines, with relatively few manipulations. The device allows variable displacement ratio to be used, giving rise to variable loading ratio. A series of experimental biaxial tension-tension tests on cruciform specimens made of composite material have been carried out using samples in which the fiber direction is perpendicular to the loading plane. Strain gages have been used in both loading directions and at both sides of the specimen, to monitor the bending parameters. Values below $5 \%$ for the previously mentioned bending parameter have been achieved at the instant of failure. The device allows, in the tension-compression configuration, the use of standard (straight) specimens, by substituting the grips by pushers in the compression loading direction. The device has been designed to be used up to $20 \mathrm{KN}$.
\end{abstract}

KEYWORDS: biaxial testing, cruciform specimens, composite materials.

\section{INTRODUCTION}

Biaxial testing machines are more expensive than uniaxial ones, but failure characterization of materials under biaxial stress states gives more realistic and useful information, than the extrapolation of uniaxial failure results. This fact is even clearer in the case of fibrous composite materials, due to the heterogeneity and anisotropic nature of the material.

This work has explored the possibility of manufacturing a device for performing biaxial testing using a uniaxial testing machine. The device has been conceived to give tensiontension, tension-compression and compression-compression loading with variable loading ratio (different load value in each axis). Very simple manipulations are to be done to change from one loading system to another. The device allows testing of cruciform specimens (typically used for the tension-tension test) as well as standard straight samples (typically used in the tension-compression test).

One of the main limitations of these kinds of in-house devices appears associated to the 
correct alignment of the loading axes. Special attention has been paid to this fact and all experiments have been monitored with strain gages at both sides of the samples and at each loading direction. The bending parameter for each axis has been maintained below a $5 \%$ along both loading axes, which is an excellent value for such an artisanal device.

The device allows exploring the role of a secondary stress in the failure ofunidirectional larninates with the fiber direction perpendicular to the plane of the cruciform $\mathrm{sa}_{\mathrm{m} p}$ le. See Correa et al [1] for further information.

\section{DESIGN AND MANUFACTURING OF THE BIAXIAL DEVICE}

Previously to the design of the device, sorne previous proposals have been revised. Hoferlin et al [2] used independent actuators for each loading axis. Another altemative can be achieved by $\mathrm{si}_{\mathrm{m}} \mathrm{p}$ ly using a device to perform biaxial tests using uniaxial testing machines without additional actuators, Ferron and Makinde [3] presented a tensiontension fixture, an analogous fixture was proposed by Tasan et al. [4], Fraunhofer [5] a device for tension-tension with lower mechanical links and Bhatnagar et al [6] proposed a device allowing equibiaxial and non-equibiaxial tension over a short range.

As mentioned in the Introduction Section, the device designed and manufactured in this work allows tension-tension and $\mathrm{co}_{\mathrm{mp}}$ ression- $\mathrm{Co}_{\mathrm{mp}}$ ression $\left(\mathrm{see} \mathrm{Fi}_{\mathrm{gur}} \mathrm{e}\right.$ la) as well as tension-compression (see $\mathrm{Fi}_{\mathrm{g}} \mathrm{e} \mathrm{lb}$ ) with different loading ratios to be introduced. It is also useful for tension-compression tests with standard (non-cruciform) test specimens, by the substitution ofthe gripping system by two flat indenters (Figure lb). In Figure 1, the two cylindrical columns represent the load frame of typical uniaxial testing machines, the dimensions of the device having been designed to be used in an Instron $\mathbb{R}$ 4481 or any other with a higher clearance between the machine load frames.

The device shown in Figure 1 has four linear guides, with an allowable vertical load of $14 \mathrm{KN}$ for each guide. The dimensions and drill positions of the fixture over the carriage have been designed to minimize the bending moment perpendicular to the carriage axis.

a)

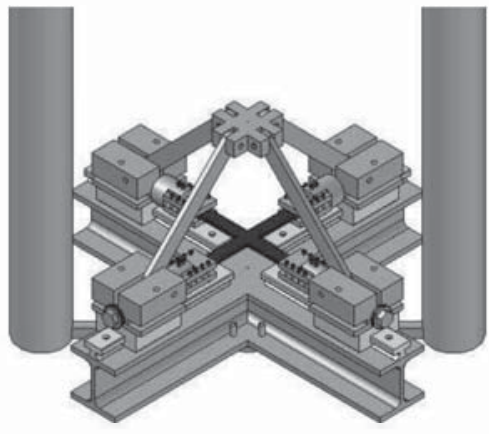

b)

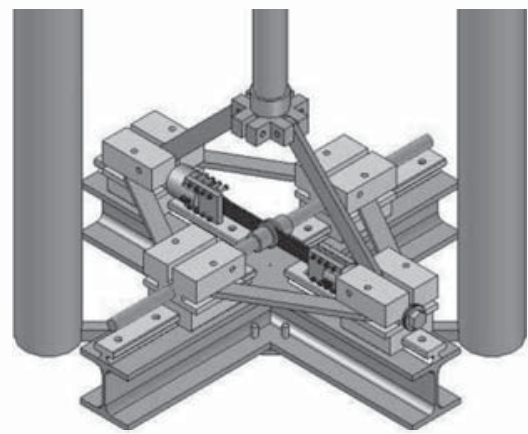

Fig. I. Device configurations for a) tension-tension with cruciform specimens and b) tension-compression with standard straight specimens.

Up to three different ways to transrnit the load to the specimen were conceived and manufactured (see $\mathrm{Fi}_{\mathrm{g} \mathrm{u} \mathrm{r}} \mathrm{e} 2$ ). A first system consisting of rigid grips $\left(\mathrm{Fi}_{\mathrm{g} \mathrm{u} \mathrm{r}} \mathrm{e} 2 \mathrm{a}\right.$ ) which 
could be opened or closed by a set of screws. The system was very tedious to install and uninstall and could not achieve a satisfactory $\mathrm{ali}_{\mathrm{g} \mathrm{m}}$ ent (a high bending parameter) of the specimen.
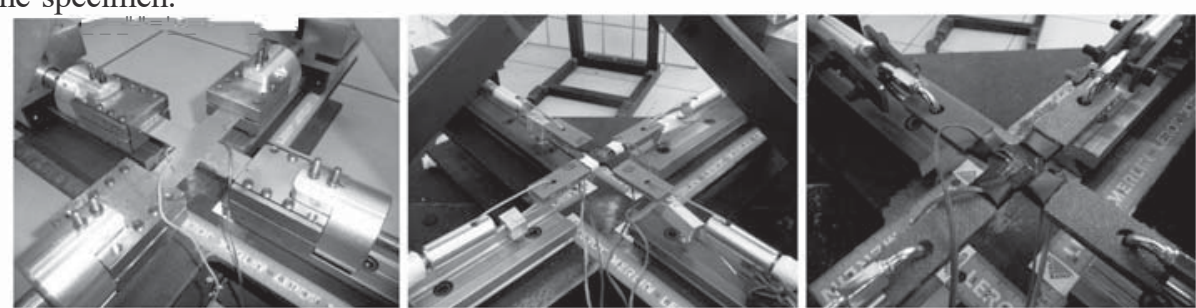

Fig. 2. Load transmission systems, a) rigid jaws, b\} flexible wire, e) rigid ring.

A second option consisted in using a flexible steel wire $\left(\mathrm{Fi}_{\mathrm{g} \mathrm{u} \mathrm{r}} \mathrm{e} 2 \mathrm{~b}\right)$, acting as a selfalignment device. This second option resulted also in a not easy-to-use procedure due to a difficult adjustment ofthe clearances produced by the wires.

A third option which gave the best results consisted in using rigid rings $\left(\mathrm{Fi}_{\mathrm{g} \mathrm{u}} \mathrm{e} 2 \mathrm{c}\right.$ ). These rings also acted as self-alignment devices but their fixed length and the way to fixed them to the specimens was much easier than the previous ones.

It is important to clarify than, in particular, the options shown in $\mathrm{Fi}_{\mathrm{g} \mathrm{u} \mathrm{r}}$ es $2 \mathrm{~b}$ and $2 \mathrm{c}$, could be used in the specimen under study due to the fact that the strength of the specimen was low (the fiber orientation is perpendicular to the specimen plane). Both the flexible wire and the rigid ring option could be installed through a hole at the ends of the sample arms. As can be seen in $\mathrm{Fi}_{\mathrm{g} \mathrm{u} \mathrm{r}} \mathrm{e}$ the specimens were prepared with tabs made of glass fiber to avoid premature failure at the hole where the load is applied.

\section{DESIGN AND MANUFACTURING OF CRUCIFORM SAMPLES}

The design of cruciform samples was taken from the work of Correa et al [7]. Basically

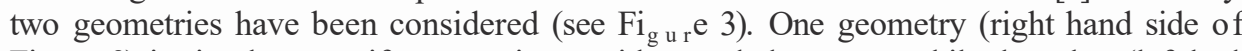
$\mathrm{Fi}_{\mathrm{g} \mathrm{u} \mathrm{r}}$ e 3 ) is simply a cruciform specimen with rounded comers, while the other (left had side of $\mathrm{Fi}_{\mathrm{gu}}$ re 3 ) is a double-rounded cruciform specimen. All the stress analysis of these specimens is discussed in [7].

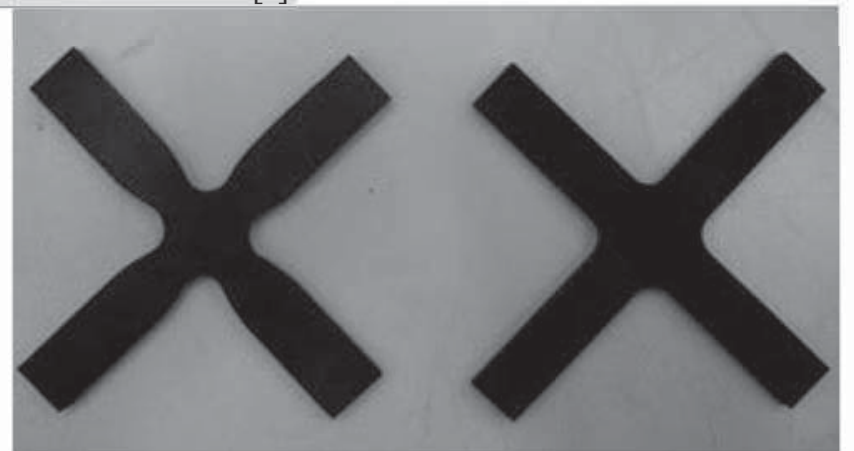

Fig. 3. The two specimen geometries used for the test.

One of the particularities of the manufacturing is that, in contrast with most of the typical specimen confi $_{\mathrm{g} \text { u }}$ ations, the fiber direction is perpendicular to the specimen 
plane, because the failure which is being analyzed is a transverse failure. This particular fiber orientation makes the lamination of the sample also to be a little bit special. Several plies of unidirectional laminas were laminated and cured together with other equal laminate creating a cross (see Figure 4). Then slices were cut using a water refrigerated diamond disk. The final shape was achieved with a final lateral machining using as a master copy a metallic sample with the desired shape, previously machined with a numerical control tooling.

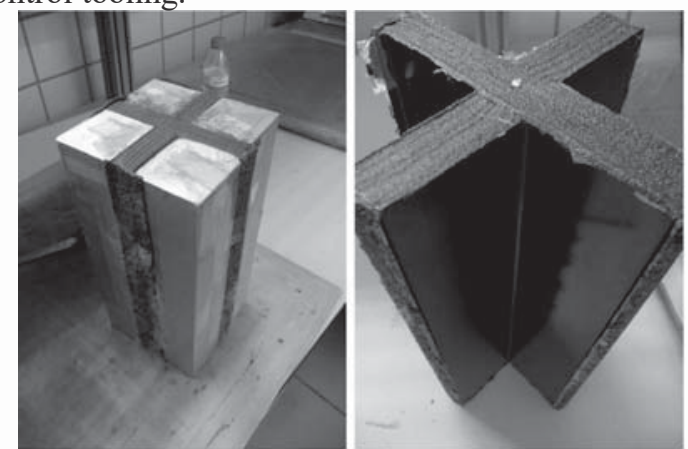

Fig. 4. Manufacturing of the test samples.

\section{RESULTS}

Preliminary results of cruciform specimens in tension-tension have been carried out. Excellent results in terms of the bending parameter, evaluated using ASTM E 1012, have been obtained with very simple adjustments of the loading device. See for example the results ofthe bending parameter, for sample $\mathrm{N}^{\circ} 18$, shown in Figure 5. As four strain gages have been bonded in the center ofthe sample (two along each loading axis, one at the bottom and one at the top surface), the bending parameter has been evaluated for both axes. In this work, only the stress state at failure is of crucial importance and as can be observed in Figure 5, the bending parameter is around I\% or 2\%, in fact it is below $5 \%$ for almost all the loading history.

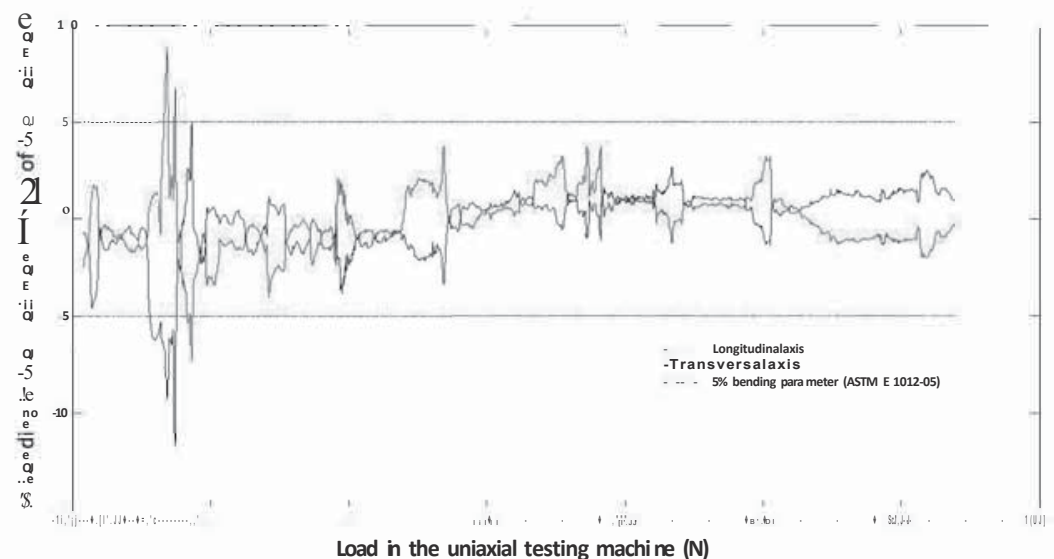

Fig. 5. Bending parameter for sample No.18. 


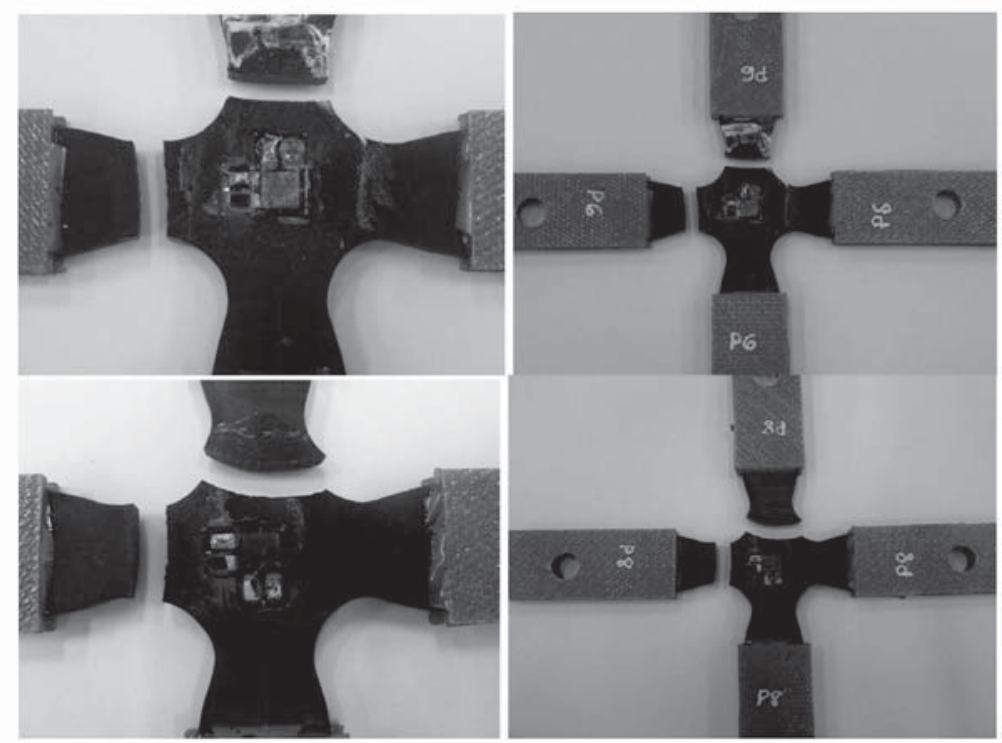

Fig. 6. Samples No.6 and No.8 after failure.

Although the design of the geometry of the samples minimizes the stress concentrations at the fillets, all tested samples have failed along the arms. A new design of the samples, with a reduced value of the thickness at the central part of the cruciform area is being explored to enforce failure at the central part of the specimen. See Correa et al [7] for further information.

Figure 7 shows the summary of tension-tension results, which have been obtained for stress ratios $\left(n_{a}\right)$ varying from $n_{a}=0.6$ (transverse stress is $60 \%$ of the main longitudinal stress) to apure biaxial $\left(\mathrm{n}_{\mathrm{a}}=1\right)$ stress state. The dispersion obtained is very high and new experiments with the reduced thickness samples are to be done. In any case, the device has demonstrated to be able to produce biaxial loadings, with variable ratio and an excellent alignment (bending parameter) value. Also, tensile test on cruciform specimens ( $\mathrm{n}_{\mathrm{a}}=-0.3$ dueto the sample geometry) are included in Figure 7.

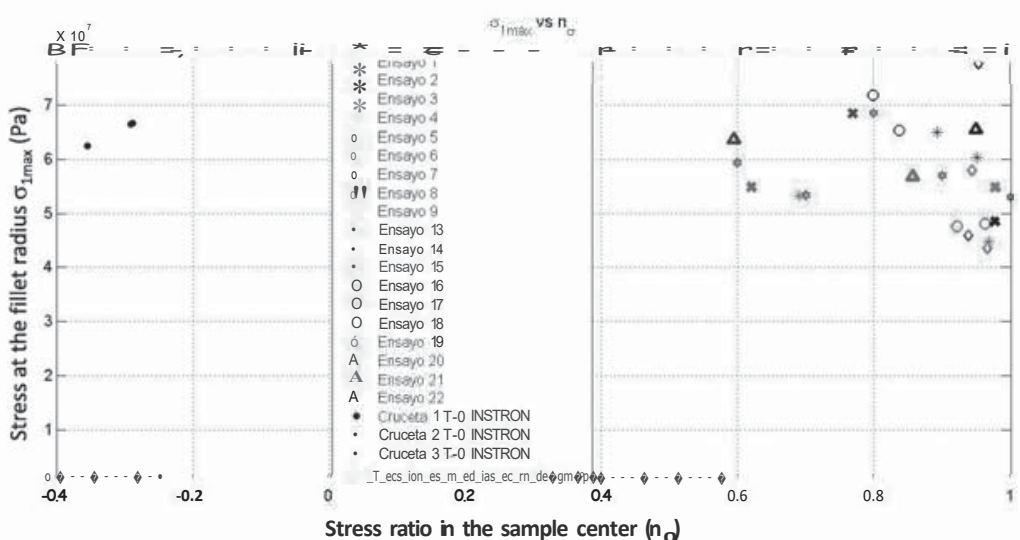

Fig. 7. Summary of tension-tension results with variable ratio. 


\section{CONCLUSIONS}

A device for inducing a biaxial stress state in cruciform specimens using a uniaxial testing machine has been conceived and manufactured. The device allows, with few manipulations, to perform tension-tension as well as tension-compression test with variable ratio.

The device has shown to induce an excellent aligned biaxial loading, with a bending parameter below $5 \%$ in all cases. This fact has allowed carrying out a preliminary testing oftension-tension cruciform samples of composite material.

The manufacturing of cruciform samples with the fiber direction perpendicular to the sample plane has been done, to the best authors' knowledge, for the first time.

\section{ACKNOWLEDGMENTS}

This work was supported by Ministerio de Ciencia e Innovación through project MAT2009-14022, Junta de Andalucía and European Social Fund through the Projects of Excellence P08-TEP-4071 and P08-TEP-4051.

\section{REFERENCES}

1 PARÍS F., CORREA E., CAÑAS J. (2003). Micromechanical view of failure of the matrix in fibrous composite materials. Campos Sci Technol, 63,pp. 1041-1052.

2 HOFERLIN, E., VAN BAEL, A., VAN HOUTTE, P., STEYAERT, C. and DE MAR, C. (1998). Biaxial test son cruciform specimens for the validation of crystallographic yield loci. Journal of Materials Processing Technology 80-81, pp. 545-550.

3 FERRON, G. and MAKINDE, A. (1988). Design and development of a biaxial strength testing device. Journal of Testing and Evaluation 16, pp. 253-256.

4 TASAN, C.C., HOEFNAGELS, J.P.M., QUAAK, G. and GEERS, M.G.D. (2008). In-Plane Biaxial Loading of Sheet Metal until Fracture in "Proceedings of the $\mathrm{x} \mathrm{f}^{\mathrm{h}}$ International Congress and Exposition", Orlando, Florida, USA.

5 FRAUNHOFER, Dynamic Material Testing. (http://www.emi.fraunhofer.de) (2005).

6 BHATNAGAR, N., BARDWAJ, R. SELVAKUMAR, P. and BRIEU, M. (2007). Development of a biaxial tensile test fixture for reinforced thermoplastic composites. Polymer Testing 26,pp. 154-161.

7 CORREA, E., BARROSO, A., PÉREZ, M.D. and PARÍS, F. (2013). Design of a cruciform specimen for biaxial transverse test. Proceedings of the $1 \mathrm{f}^{\mathrm{h}}$ Coriference on Composite Materials MATCOMP-13. Algeciras (Cádiz), 2-5 July 2013. 